\title{
The Effects of Morphine on Diet Selection Are Dependent Upon Baseline Diet Preferences
}

\author{
BLAKE A. GOSNELL, DEAN D. KRAHN AND MARK J. MAJCHRZAK \\ University of Michigan, Department of Psychiatry \\ University Hospital, 8D8806, Box 0116, Ann Arbor, Michigan 48109-0116
}

Received 4 June 1990

\begin{abstract}
GOSNELL, B. A., D. D. KRAHN AND M. J. MAJCHRZAK. The effects of morphine on diet selection are dependent upon baseline diet preferences. PHARMACOL BIOCHEM BEHAV 37(2) 207-212, 1990. - It has been reported that morphine causes a selective increase in the intake of dietary fat. Because we have noted considerable variability among rats in their preferences for carbohydrate and fat, we reasoned that the effect of morphine on diet selection may differ in fat-preferring vs. carbohydrate-preferring rats. Male Sprague-Dawley rats were given ad lib access to separate sources of carbohydrate, fat and protein (Experiment 1), or to a carbohydrate/protein and a fat/protein diet (Experiment 2). After daily baseline intakes of the diets were determined, all rats were tested for feeding responses to subcutaneous injections of morphine $(0,2$ and $10 \mathrm{mg} / \mathrm{kg})$. Significant positive correlations were found between baseline daily intake of a given diet and the effect of morphine on the intake of that diet. Generally, morphine increased carbohydrate intake in carbohydrate-preferring rats, and increased fat intake in fat-preferring rats. These results suggest that the effect of morphine is to increase intake of a preferred diet rather than to increase intake of a specific macronutrient.
\end{abstract}

Opioids Diet selection Protein Morphine Carbohydrate Macronutrient Food intake Fat Feeding

SEVERAL studies have reported that the administration of morphine causes a selective increase in the intake of dietary fat. In rats on a restricted feeding schedule, morphine increased fat intake and reduced or had no effect on carbohydrate and protein intake $(13,14)$. A similar pattern has been observed when rats were given repeated daily injections of morphine $(15,17)$ or given drinking water adulterated with morphine (16). Another opioid agonist, butorphanol, has also been found to cause preferential increases in the intake of a high-fat diet (19). On the other hand, Shor-Posner et al. (21) found that in nondeprived rats, morphine increased protein intake and had no significant effect on fat or carbohydrate intake. In food-restricted rats, however, these authors found that morphine increased fat intake and decreased carbohydrate intake, an effect similar to that reported by Marks-Kaufman (13) and Marks-Kaufman and Kanarek (14). More recently, Evans and Vaccarino (7) reported that morphine increased the intake of a protein-rich diet in protein-deprived rats, and slightly increased intake of a carbohydrate-rich diet in carbohydrate-deprived rats. When sweetened chow was available along with unsweetened chow, morphine selectively increased intake of the preferred sweetened chow. It thus appears that the effect of morphine may be to increase intake of the more preferred food. However, Marks-Kaufman and Kanarek (15) have pointed out that morphine selectively increases fat intake even when fat is not the most preferred nutrient $(13,14)$.

In our studies on food intake and diet selection, we have noted that when rats are given separate sources of protein, fat and carbohydrate, there are considerable individual differences in the relative intakes of fat and carbohydrate. Some rats consume carbohydrate and protein almost exclusively, whereas others consume primarily fat and protein. We reasoned that if the effect of morphine is to stimulate intake of the preferred diet, diet selection after morphine treatment should correspond to some degree to baseline diet preferences. On the other hand, if morphine causes a selective increase in fat intake, baseline diet preferences should be unrelated to the effects observed after morphine treatment.

\section{EXPERIMENT 1: EFFECTS OF MORPHINE ON THE INTAKES OF} CARBOHYDRATE, FAT AND PROTEIN

\section{Method}

Male Sprague-Dawley rats (Charles River, Wilmington, MA) were individually housed in stainless steel cages in a room in which the lights were on from $7 \mathrm{a} . \mathrm{m}$. to $7 \mathrm{p} . \mathrm{m}$. The rats were placed on a diet regimen in which carbohydrate, fat and protein were available in separate glass jars anchored to the floor of each cage. The composition of the diets is shown in Table 1. All components of the diets were purchased from ICN Biochemicals (Cleveland, $\mathrm{OH}$ ), with the exception of DL-methionine and choline chloride (Sigma Chemical Co., St. Louis, MO), sucrose (Mallinckrodt, Paris, KY), and vegetable shortening (Crisco), which was purchased locally. As indicated in the table, all diets, when equated on a caloric basis, contained equal amounts of vitamins, minerals, choline chloride and fiber. All diets were available ad lib except for brief periods (less than $1 \mathrm{hr}$ ) prior to 
TABLE 1

COMPOSITION OF DIETS USED IN EXPERIMENT 1

\begin{tabular}{lccc}
\hline & \multicolumn{3}{c}{ Diet } \\
& Carbohydrate & Fat & Protein \\
\hline & & & \\
Corn Starch & 57.7 & - & - \\
Dextrin & 28.8 & - & - \\
Sucrose & 9.6 & - & - \\
Casein* & - & - & 105.0 \\
DL-Methionine & - & - & 1.6 \\
Vegetable Shortening & - & 40.6 & - \\
Safflower Oil & - & 2.1 & - \\
AIN-76A Vitamin Mix $\dagger$ & 1.0 & 1.0 & 1.0 \\
AIN-76 Mineral Mix $\dagger$ & 3.5 & 3.5 & 3.5 \\
Choline Chloride & 0.2 & 0.2 & 0.2 \\
Cellulose (Alphacel) & 5.0 & 5.0 & 5.0 \\
Weight (g) & 105.8 & 52.4 & 116.3 \\
Total Energy (kcal) $\ddagger$ & 390 & 390 & 387 \\
Energy Density (kcal/g) & 3.69 & 7.44 & 3.33 \\
\hline
\end{tabular}

\footnotetext{
All components are expressed as weight (grams).

*Assuming a protein content of $90 \%$.

$\dagger$ The vitamin and mineral mixes contain 97 and $12 \%$ sucrose, respectively.

$\ddagger$ Based on energy values of 4,9 and $4 \mathrm{kcal} / \mathrm{g}$ for carbohydrate, fat and protein.
}

drug test sessions (see below), during which the diet jars were removed for refilling and weighing. The positions of the jars were changed daily, and were refilled as needed. After 8 days of adaptation to these diets, baseline daily intakes were measured for three consecutive days. All measurements of each diet were adjusted for spillage. At the beginning of these measurements, body weights ranged from $262-296 \mathrm{~g}$.

One day after determinations of baseline diet selection, rats were tested for the effects of morphine sulfate [0 $(\mathrm{NaCl}), 2$ and 10 $\mathrm{mg} / \mathrm{kg}, \mathrm{SC}]$ on diet selection. Morphine sulfate was obtained through the University of Michigan Hospital Pharmacy as a 30 $\mathrm{mg} / \mathrm{ml}$ solution. Each $\mathrm{ml}$ also contained $7.05 \mathrm{mg}$ of sodium chloride and as preservatives, $1 \mathrm{mg}$ of sodium bisulfite and $5 \mathrm{mg}$ of chlorobutanol. For injection in a $1 \mathrm{ml} / \mathrm{kg}$ volume, this solution was diluted to the appropriate concentration with normal saline. All rats were tested with all doses, and test days were two days apart. The order of testing of the doses was varied across rats such that all sequences were represented at least twice. Injections were given approximately $3-3.5 \mathrm{hr}$ after the onset of the light period. Immediately after injection, rats were returned to their home cages containing all three diets. Intake was determined by weight 2 and $4 \mathrm{hr}$ after injection.

Intake data were analyzed initially with a two-factor repeated measures analysis of variance: morphine dose $\times$ diet. For each diet, mean intakes in the two morphine conditions were compared to the control mean intake with Dunnett's procedure (one-tailed). In all cases, the error term and degrees of freedom used in determining the significance of these contrasts was based only on the two conditions being compared (i.e., the control condition and one of the morphine dose conditions). To determine the relationship between baseline diet preferences, difference scores were computed for each diet and each morphine dose by subtracting the control intake of a particular diet (i.e., intake after saline injection) from the intake of the same diet after each morphine treatment. These difference scores were then used to calculate correlations
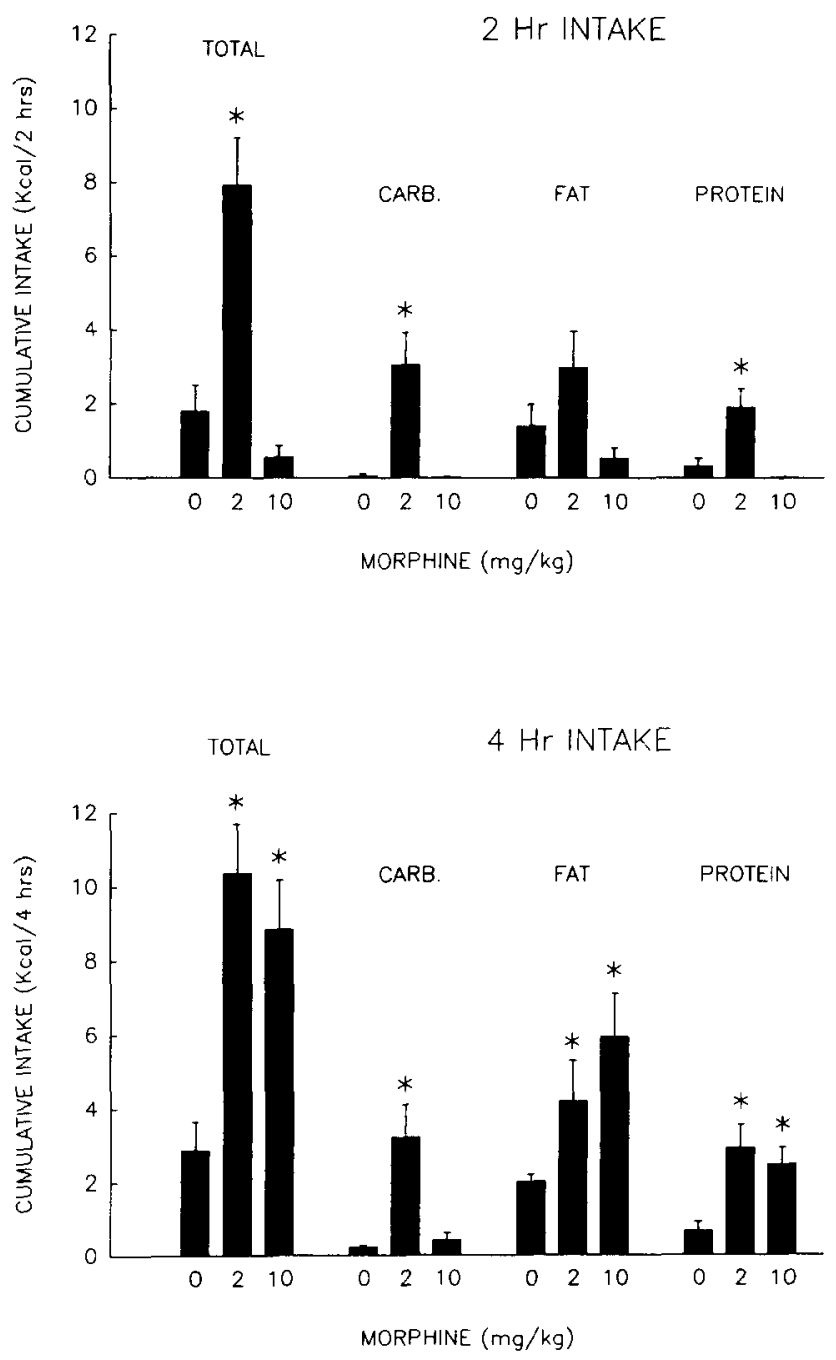

FIG. 1. Effect of morphine on the intake of carbohydrate, fat and protein. Upper panel represents 2-hr intake; lower panel represents cumulative 4-hr intake. All rats were tested with the 0,2 and $10 \mathrm{mg} / \mathrm{kg}$ doses $(n=17)$. Asterisks indicate significant differences from the corresponding control condition $(0 \mathrm{mg} / \mathrm{kg})$ (Dunnett's procedure, one-tailed, $p<0.05$ ).

(Pearson $r$ ) between the effects of morphine on nutrient intake and baseline (daily) intakes.

\section{Results}

Averaged over the 3-day baseline measurement, rats consumed an average of $98 \mathrm{kcal} /$ day. Mean carbohydrate, fat and protein intakes were $34.5 \pm 3.5,33.0 \pm 4.7$ and $30.2 \pm 1.7 \mathrm{kcal}$, respectively. The intakes of fat and carbohydrate were negatively correlated $(\mathrm{r}=-.74, p<0.05)$; protein intake was not correlated with fat or carbohydrate intake $(r=-.28$ and -.17 , respectively, $p>0.05$ ). When expressed as percentages of total intake, the percentage of calories consumed as carbohydrate ranged from 7 to $60 \%$ (mean $=36 \%)$. For fat and protein intakes, these ranges were 12 to $67 \%($ mean $=33 \%)$ and 18 to $50 \%$ (mean $=31 \%)$, respectively. When daily intakes were measured again 3 days after the final morphine test day, daily carbohydrate, fat and protein 
TABLE 2

CORRELATION COEFFICIENTS (PEARSON r) FOR RELATIONSHIPS BETWEEN DAILY NUTRIENT INTAKES VERSUS EFFECTS OF MORPHINE ON NUTRIENT INTAKE

Effect of Morphine on Intake of Each Diet (difference from control intake)

$$
2 \mathrm{mg} / \mathrm{kg} \quad 10 \mathrm{mg} / \mathrm{kg}
$$

\begin{tabular}{lllll} 
Daily Intake Carb. Fat & Protein Carb. Fat & Protein \\
\hline
\end{tabular}

\begin{tabular}{lcrrrrr}
\hline & \multicolumn{7}{c}{ 2-Hour Intake } \\
Carbohydrate & $.60^{*}$ & -.25 & -.06 & -.10 & .15 & .04 \\
Fat & $-.49^{*}$ & .38 & -.07 & -.08 & -.06 & .35 \\
Protein & .24 & -.07 & .25 & .23 & .11 & -.47 \\
& & \multicolumn{5}{c}{ 4-Hour Intake } \\
Carbohydrate & $.59 *$ & -.47 & -.18 & .20 & -.40 & .12 \\
Fat & -.46 & $.58^{*}$ & -.22 & -.02 & $.49 *$ & -.03 \\
Protein & .25 & -.13 & $.61^{*}$ & -.35 & -.14 & -.19
\end{tabular}

*Indicates a significant correlation (Pearson $\mathrm{r}$, two-tailed, $p<0.05$, $\mathrm{n}=17$ ).

intakes, averaged over a 3-day period, were $33.2 \pm 3.4,37.2 \pm 4.7$ and $26.6 \pm 2.2 \mathrm{kcal}$, respectively. Only protein intake was significantly different from the measurement prior to the morphine tests, $t(16)=3.09, p<0.05$.

A significant effect of morphine was observed at 2 and $4 \mathrm{hr}$, $\mathrm{F}(2,32)=23.48$ and 20.32 , respectively, $p<0.001$. At the $4-\mathrm{hr}$ measurement, there was also a significant effect of diet, $F(2,32)=$ $6.84, p<0.01$, and a morphine $\times$ diet interaction, $\mathrm{F}(4,64)=4.51$, $p<0.01$. As shown in Fig. 1 , the $2 \mathrm{mg} / \mathrm{kg}$ dose of morphine significantly increased 2-hr total caloric intake, and both doses increased 4-hr intake. The $2 \mathrm{mg} / \mathrm{kg}$ dose increased carbohydrate and protein intake at $2 \mathrm{hr}$, and increased the intake of all three nutrients at $4 \mathrm{hr}$. The $10 \mathrm{mg} / \mathrm{kg}$ dose had no significant effects at $2 \mathrm{hr}$, and increased fat and protein intake at $4 \mathrm{hr}$.

At $2 \mathrm{hr}$, the effect of the $2 \mathrm{mg} / \mathrm{kg}$ dose on carbohydrate intake (difference from control intake) was positively correlated with daily carbohydrate intake and negatively correlated with average daily fat intake $(p<0.05)$ (see Table 2). At $4 \mathrm{hr}$, the effect of this dose on the intake of each nutrient was significantly correlated with the average daily intake of that nutrient (all $p$ 's $<0.05$ ). The effect of the $10 \mathrm{mg} / \mathrm{kg}$ dose on fat intake was also significantly correlated to baseline fat preference (4-hr measurement).

In light of the observed correlations between the effects of morphine and diet preferences, the 4-hr data were reanalyzed after dividing the rats into groups based on the ratio of average daily carbohydrate intake to average daily fat intake. As shown in Fig. 2 (bottom), morphine stimulated fat and protein intake in fatpreferring rats (carbohydrate:fat intake ratio $<1$ ). In carbohydratepreferring rats (carbohydrate:fat intake ratio $>1$ ), the $2 \mathrm{mg} / \mathrm{kg}$ dose increased carbohydrate and protein intake, whereas the 10 $\mathrm{mg} / \mathrm{kg}$ dose increased fat and protein intake.

\section{Discussion}

These results indicate that the effect of morphine on diet selection is correlated with preexisting baseline intakes of carbohydrate, fat or protein. Considered as a group, the $2 \mathrm{mg} / \mathrm{kg}$ dose of morphine increased the intake of all three macronutrients, while the $10 \mathrm{mg} / \mathrm{kg}$ dose increased the intake of fat and protein only.

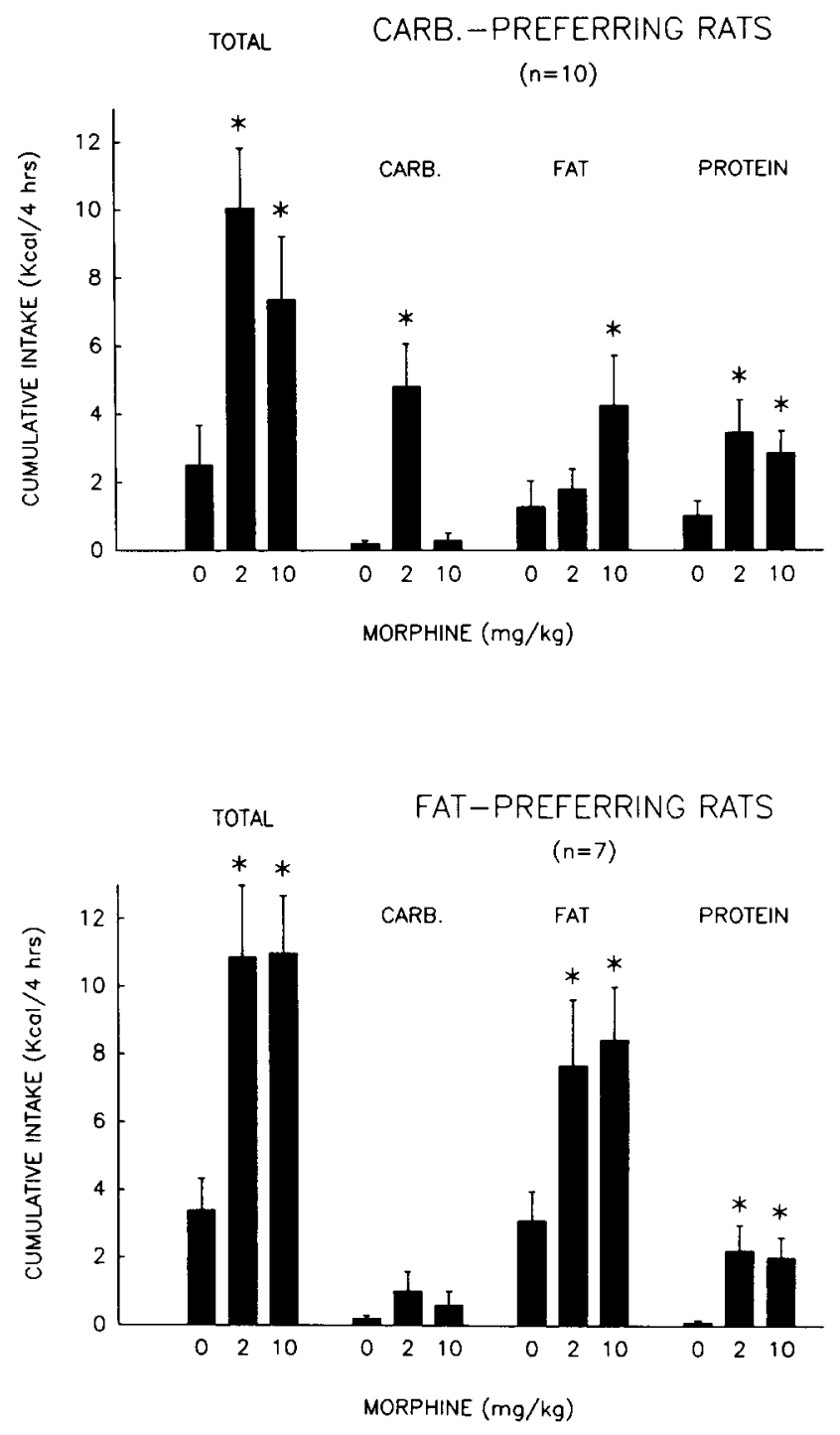

FIG. 2. Four-hour cumulative intake of carbohydrate, fat and protein after injections of morphine. Rats from Experiment 1 were divided into relative carbohydrate-preferring rats (upper panel, $n=10$ ) and relative fat-preferring rats (lower panel, $n=7$ ). See text for method of grouping. Asterisks indicate significant differences from the corresponding control condition $(0$ $\mathrm{mg} / \mathrm{kg}$ ) (Dunnett's procedure, one-tailed, $p<0.05$ ).

When baseline daily intakes of the three macronutrients were also taken into consideration, a significant correlation was found between daily intake of a given nutrient and the effect of morphine on the intake of that nutrient. To the degree that daily intakes reflect macronutrient preference, then, this conclusion is consistent with the suggestion that morphine causes a preferential increase in the intake of preferred foods (7).

Daily fat and carbohydrate intake were negatively correlated, and there was a large variability among rats in the intakes of both nutrients. Due to the apparent relationship between diet preference and the effect of morphine on diet selection, it follows that groups of rats with different baseline preferences should differ in their pattern of intake after morphine administration. This was found to be the case when rats were divided into groups of relative carbohydrate-preferrers and relative fat-preferrers. 
TABLE 3

CORRELATION COEFFICIENTS (PEARSON $r$ ) FOR RELATIONSHIPS BETWEEN DAILY NUTRIENT INTAKES VERSUS EFFECTS OF MORPHINE ON NUTRIENT INTAKE

Effect of Morphine on Intake of Each Diet (difference from control intake)

$2 \mathrm{mg} / \mathrm{kg}$

$10 \mathrm{mg} / \mathrm{kg}$

Daily Intake Carb/Protein Fat/Protein Carb/Protein Fat/Protein

\begin{tabular}{lrrrr}
\hline & \multicolumn{4}{c}{ 2-Hour Intake } \\
Carb./Protein & .27 & -.33 & -.40 & .33 \\
Fat/Protein & -.30 & $.49 *$ & .28 & $-.42^{*}$ \\
& \multicolumn{4}{c}{$4-$ Hour Intake } \\
Carb./Protein & .28 & -.34 & $.67^{*}$ & $-.55^{*}$ \\
Fat/Protein & -.29 & $.55^{*}$ & $-.61^{*}$ & $.58^{*}$ \\
\end{tabular}

*Indicates a significant correlation (Pearson $\mathrm{r}$, two-tailed, $p<0.05$, $\mathrm{n}=25$ ).

Superimposed upon the influence of baseline preferences on diet selection after morphine treatment, there appeared to be a qualitative difference in the effects of the 2 and $10 \mathrm{mg} / \mathrm{kg}$ doses. There was a tendency for the $2 \mathrm{mg} / \mathrm{kg}$ dose of morphine to be more effective at increasing carbohydrate intake than the $10 \mathrm{mg} / \mathrm{kg}$ dose. Conversely, the $10 \mathrm{mg} / \mathrm{kg}$ dose was generally more effective than the $2 \mathrm{mg} / \mathrm{kg}$ dose at increasing fat intake. This tendency is somewhat obscured in carbohydrate-preferring and fat-preferring groups, but is evident in Fig. 1, in which rats were not separated according to baseline preferences. The $2 \mathrm{mg} / \mathrm{kg}$ dose increased 4-hr intake of all three macronutrients; increases in carbohydrate intake were slightly greater than those of fat and protein. The 10 $\mathrm{mg} / \mathrm{kg}$ dose, on the other hand, increased only fat and protein intake.

Because of the wide range of intakes of fat and carbohydrate in this experiment, there were too few animals to form large enough groups with similar carbohydrate and fat preferences. Therefore, a second experiment was performed with a larger initial sample. In addition, protein selection was eliminated as a source of variation by adding a fixed amount to both a carbohydrate and a fat diet. The justification for eliminating protein selection in this case is that protein intake was not found to correlate significantly with either fat or carbohydrate intake. Furthermore, protein intake was increased to approximately the same degree in both fat-preferring and carbohydrate-preferring animals.

\section{EXPERIMENT 2: EFFECTS OF MORPHINE ON THE INTAKES OF CARBOHYDRATE/PROTEIN AND FAT/PROTEIN DIETS}

\section{Method}

Male Sprague-Dawley rats were housed and maintained in a manner similar to that described in Experiment 1, with only a few exceptions. Each rat was presented with only two diets: a carbohydrate-protein diet (CP) and a fat-protein diet (FP) (see Table 1). These diets were similar to the carbohydrate and fat diets described in Table 1, except that $20 \%$ of the energy derived from carbohydrate (or fat) was replaced with casein and DL-methionine. On a caloric basis, both diets contained the same amounts of vitamins, minerals, choline chloride and fiber as shown in Table 1. The ratio of starch:dextrin:sucrose was kept constant (60:30:10), as was the ratio of vegetable shortening:safflower oil (95:5). The
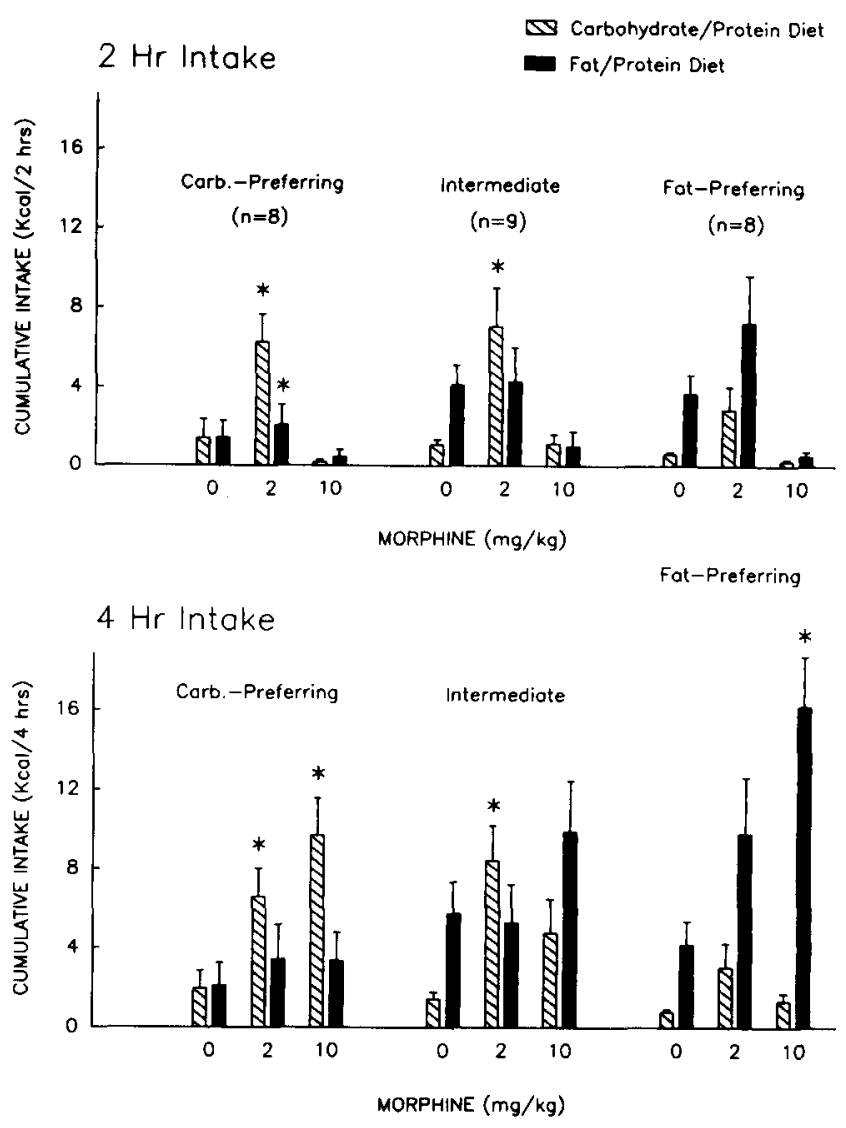

FIG. 3. Two- and four-hour cumulative intakes of carbohydrate/protein and fat/protein diets after injections of morphine $(0,2$ or $10 \mathrm{mg} / \mathrm{kg})$. Rats were divided into carbohydrate-preferring, intermediate and fat-preferring groups on the basis of average daily intakes of the two diets; all rats were tested with the 0,2 and $10 \mathrm{mg} / \mathrm{kg}$ doses. Asterisks indicate significant differences from the corresponding control condition $(0 \mathrm{mg} / \mathrm{kg}$ ) (Dunnett's procedure, one-tailed, $p<0.05$ ).

CP diet therefore contained $80 \%$ carbohydrate and $20 \%$ protein $(3.61 \mathrm{kcal} / \mathrm{g})$ and the FP diet contained $79.6 \%$ fat, $20 \%$ protein and $1.4 \%$ carbohydrate (due to sucrose in the vitamin and mineral mixes) $(5.95 \mathrm{kcal} / \mathrm{kg})$. For the first 6 days of access to these diets, positions of the jars were not changed; thereafter, positions were reversed daily. After 6 additional days of adaptation to these diets, daily intakes were determined for two consecutive days. At the beginning of these measurements, body weights ranged from 282-387 g. Three days later, the effects of morphine were determined in a manner similar to that described in Experiment 1. Morphine $(0,2$ and $10 \mathrm{mg} / \mathrm{kg}$ ) was injected in a $0.5 \mathrm{ml} / \mathrm{kg}$ volume. Only one-half of the animals were tested on a given day, but there were two days between trials for all rats. Injections were given approximately $2.5-3 \mathrm{hr}$ after the onset of the light period.

For data analysis, rats were first divided into CP-preferring, FP-preferring and intermediate groups. This was accomplished by rank-ordering all rats according to the ratio of $\mathrm{CP}$ diet intake to total intake. The 8 rats with the highest and the lowest ratios were designated CP-preferring and FP-preferring groups, respectively. The remaining 9 rats $(n=9)$ comprised the intermediate group. Data were then analyzed with a 3-factor analysis of variance: morphine dose $\times$ diet $\times$ baseline preference. Within each preference group, Dunnett's procedure was used to compare mean 
intakes of each nutrient after morphine treatment with control intakes of that nutrient.

\section{Results}

As was observed in Experiment 1, intakes of carbohydrate and fat were negatively correlated $(\mathrm{r}=-.88, p<0.05)$. As a group $(n=25)$, average caloric intakes from the two diets were nearly identical $(51.0 \pm 4.6 \mathrm{kcal}$ from the CP diet, $50.9 \pm 5.3 \mathrm{kcal}$ from the FP diet). When divided into groups on the basis of the ratio of CP diet intake to total intake, the carbohydrate-preferring, intermediate and fat-preferring groups all significantly differed from one another in their intakes of the CP diet $(75.5 \pm 4.7,52.3 \pm 2.1$ and $25.0 \pm 4.5 \mathrm{kcal}$, respectively) and in intakes of the FP diet $(24.7 \pm 4.9,47.9 \pm 3.4$ and $80.4 \pm 6.5 \mathrm{kcal}$, respectively) $(p<0.01$, two-tailed Bonferroni test). The mean body weights of the three groups were not significantly different at the beginning of the daily intake measurements $(328 \pm 9,333 \pm 4$ and $341 \pm 10 \mathrm{~g}$ for the carbohydrate-preferring, intermediate and fat-preferring groups, respectively, $p>0.05$ ).

There was a significant effect of morphine on 2- and 4-hr intake, $F(2,44)=41.45$ and $26.17, p<0.001$. At $4 \mathrm{hr}$, the following interactions were significant: diet $\times$ preference group, $\mathrm{F}(2,22)=$ $7.15, p<0.005$; diet $\times$ morphine, $\mathrm{F}(2,44)=4.64, p<0.02$; diet $\times$ morphine $\times$ preference group, $\mathrm{F}(4,44)=8.05, p<0.001$. These interactions approached significance at the $2 \mathrm{hr}$ measurement $(0.05<p<0.10)$. The effect of diet at $4 \mathrm{hr}$ also approached significance $(p=0.057)$. As is shown in Fig. 3, the source of these interactions appears to be due to the differential effects of morphine on diet selection in the three preference groups. Both doses of morphine significantly stimulated 4-hr total intake in all groups; $2-\mathrm{hr}$ intake was increased by the $2 \mathrm{mg} / \mathrm{kg}$ dose in the carbohydrate- and fat-preferring groups. In the carbohydratepreferring group, these increases were due almost exclusively to an increased intake of the CP diet. Conversely, the increased intake in the fat-preferring group was due primarily to an increased intake of the FP diet. In the intermediate group, the intake of both diets was increased: the $2 \mathrm{mg} / \mathrm{kg}$ dose increased intake of the $\mathrm{CP}$ diet, whereas the $10 \mathrm{mg} / \mathrm{kg}$ dose increased intake of both diets.

When the effects of morphine were considered in conjunction with baseline daily intakes of the CP and FP diets, the pattern of significant correlations was similar to that observed in Experiment 1. With rats from all groups pooled $(n=25)$, there was a significant positive correlation between the effect of the $2 \mathrm{mg} / \mathrm{kg}$ dose on fat intake and average daily intake of the fat diet. Curiously, there was a significant negative correlation between the effect of the $10 \mathrm{mg} / \mathrm{kg}$ dose on fat intake and daily fat intake. This may be due in part to the initial cataleptic effect of this dose of morphine. At $4 \mathrm{hr}$, the effect of the $10 \mathrm{mg} / \mathrm{kg}$ dose on the intake of each diet was positively correlated with baseline daily intake of that diet and negatively correlated with baseline intake of the other diet (all $p$ 's $<0.05$ ).

Three days after the completion of the morphine tests, daily intake of the two diets was measured again for 2 consecutive days. Again, the carbohydrate-preferring, intermediate and fat-preferring groups all significantly differed from one another in their intakes of the CP diet $(62.6 \pm 4.9,41.9 \pm 3.3$ and $24.3 \pm 3.5 \mathrm{kcal}$, respectively) and in intakes of the FP diet $(33.7 \pm 6.0,54.5 \pm 3.0$ and $74.9 \pm 6.8$, respectively) $(p<0.05$, two-tailed Bonferroni test). For the fat-preferring group, these average intakes did not significantly differ from those observed prior to morphine testing ( $p>0.05$, two-tailed repeated measures $t$-tests). The intermediate group consumed significantly less of the $\mathrm{CP}$ diet on the second measurement, $t(8)=2.69, p<0.05$. The carbohydrate-preferring group tended to consume more of the FP diet and less of the CP diet than when measured before morphine tests, but these differences fell just short of the significance criterion of $p<0.05$. At the completion of these measures of daily intake, mean body weights for the carbohydrate-preferring, intermediate and fat-preferring groups were $402 \pm 12,406 \pm 8$ and $425 \pm 15 \mathrm{~g}$, respectively. Although the fat-preferring group tended to weigh more than the other groups, there were no significant differences among the groups.

\section{GENERAL DISCUSSION}

Large individual differences in diet selection allowed the identification of groups of rats characterized as either fat-preferring or carbohydrate-preferring, and this preference was found to correlate with the changes in food intake and diet selection observed after systemic injections of morphine. Rats that normally consumed most of their energy as carbohydrate consumed primarily carbohydrate after morphine administration. Similarly, the primary effect of morphine in fat-preferring rats was to stimulate fat consumption. These results provide strong support to the suggestion that the effect of morphine is to preferentially increase intake of a preferred food rather than to stimulate intake of a particular macronutrient (7).

The effect of morphine on diet selection appears to be influenced by the deprivation status of the animals. The selective increases in fat intake reported by Marks-Kaufman (13) and Marks-Kaufman and Kanarek (14) were obtained with rats on a restricted feeding schedule. Shor-Posner et al. (21) obtained similar results in food-restricted rats, but found that in nondeprived rats, morphine selectively increased protein intake. Bhakthavatsalam and Leibowitz (2) reported that in nondeprived rats, morphine increased the intake of all three macronutrients, although the increases in fat and protein intake were greater than that of carbohydrate intake (2). In the present experiments with nondeprived rats, the intakes of all macronutrients were increased in some cases, though the pattern of increases was found to depend on baseline preferences. On the other hand, two studies with chronic morphine exposure reported exclusive increases in fat intake in nondeprived rats $(16,17)$. It is interesting to note that when morphine was added to the drinking water (16), only those animals with a high predrug preference for fat consumed the morphine solution.

It has been pointed out that differences in baseline feeding may account for some of the apparent discrepancies in the literature. Shor-Posner et al. (21) noted that the rats used in the study by Ottaviano and Riley (17) (which reported no effect of morphine on protein intake) consumed very little protein at baseline. MarksKaufman and Kanarek (15) suggested the possibility that their observed selective stimulation of fat intake may be due in part to the fact that, before testing, rats consumed more fat than carbohydrate or protein [see also (17)]. It may be important to note that repeated cycles of food restriction and refeeding have been reported to cause an increase in dietary fat selection (18). However, Marks-Kaufman and Kanarek $(13,14)$ observed selective morphine-induced increases in fat intake even in conditions in which fat was not the most preferred nutrient at baseline. The present experiments, which specifically considered the potential confound of baseline diet preferences, suggest that baseline preferences greatly affect the feeding response to morphine.

Most studies on the effects of morphine on diet selection have used only one dose $(2-2.5 \mathrm{mg} / \mathrm{kg})(2,7,15,21)$ or a range of high doses $(10-30 \mathrm{mg} / \mathrm{kg}$ ) (14). One exception is a report by MarksKaufman (13), in which doses of 1,10 and $20 \mathrm{mg} / \mathrm{kg}$ were used. She obtained similar effects with the 1 and $10 \mathrm{mg} / \mathrm{kg}$ doses in food-restricted rats: an increase in fat intake and a decrease in 
carbohydrate intake. In the present report, however, there appear to be qualitative as well as quantitative differences in the effects of the 2 and the $10 \mathrm{mg} / \mathrm{kg}$ doses. Generally, only the $2 \mathrm{mg} / \mathrm{kg}$ dose increased 2-hr intake, whereas both doses increased 4-hr intake. This delay in the effect of the higher dose can be attributed to the sedation and/or catalepsy which was quite apparent within the first hour postinjection. Qualitatively, carbohydrate was increased more by the 2 than by the $10 \mathrm{mg} / \mathrm{kg}$ dose, whereas the $10 \mathrm{mg} / \mathrm{kg}$ dose was more effective in stimulating fat intake. This tendency is best observed in Fig. 1, in which rats were not separated according to baseline preferences, and in the intermediate group in Experiment 2 . As Fig. 3 illustrates, the $2 \mathrm{mg} / \mathrm{kg}$ dose increased intake of the carbohydrate/protein diet only, whereas the $10 \mathrm{mg} / \mathrm{kg}$ dose caused slightly larger increases in fat/protein intake than in carbohydrate/protein intake.

Genetic differences in the acceptability of various diets have been identified (20), and certain experimental manipulations (e.g., weight cycling) have been shown to alter preferences (18). Although the causes of the observed differences in preferences in the present studies are not clear, they appeared to be relatively stable, as indicated by the small variations in day-to-day diet selection (measured over 2-3 days), as well as by the similar selection patterns exhibited by the various groups when retested after morphine tests. A similar heterogeneity in diet selection has been noted in other studies, even when the positions of the nutrients are left unchanged throughout the experiment (unpublished observations). It would be of interest to determine whether the effect of morphine on diet selection could be modified by prior manipulation of baseline preferences.

Although rats in the present report are referred to as either carbohydrate- or fat-preferring, it should be noted that the observed differences in diet preference may also reflect differences in the preference for other attributes of the diets, such as taste and texture. The high-carbohydrate diets have a powdery consistency, whereas the high-fat diets are solid with a greasy texture. Regardless of the basis for the observed diet preferences, however, these results clearly show that these preferences are important determinants of the feeding response to morphine.

Several studies have suggested that opioids play a role in the rewarding or pleasurable aspects of taste $(3-5,9,12)$. Generally, opioid agonists increase intake and/or preference for saccharin or glucose solutions, while antagonists decrease preferences. However, this effect of opioids is not limited to sweet tastes, as similar results have been observed with salt solutions $(1,10,11)$. Yeomans et al. (22) recently reported that the opioid antagonist nalmefene reduced food intake in human subjects, and that the intake of palatable foods was reduced more than the intake of foods rated less palatable. Fantino et al. (8) found that naltrexone reduced pleasantness ratings of glucose and food-related odors. Similarly, we have reported in abstract form that the antagonist naloxone causes decreases in pleasantness ratings for taste stimuli containing various concentrations of sugar and fat (6). These studies, along with the present results and the recent report by Evans and Vaccarino (7), are consistent in suggesting that opioids play a role in the mediation of food preference and palatability that is not taste- or macronutrient-specific. The results presented here also indicate that the close examination of baseline diet preferences and of individual differences in preferences may be a useful approach in further study of the neurochemical control of ingestion.

\section{ACKNOWLEDGEMENTS}

We thank Drs. Allen S. Levine and Dale R. Romsos for their advice on diet compositions. This research was supported by NIDA grant DA05471.

\section{REFERENCES}

1. Bertino, M.; Abelson, M. L.; Marglin, S. H.; Neuman, R.; Burkhardt, C. A.; Reid, L. D. A small dose of morphine increases intake of and preference for isotonic saline among rats. Pharmacol. Biochem. Behav. 29:617-623; 1988.

2. Bhakthavatsalam, P.; Leibowitz, S. F. Morphine-elicited feeding: Diurnal rhythm, circulating corticosterone and macronutrient selection. Pharmacol. Biochem. Behav. 24:911-917; 1986.

3. Calcagnetti, D. J.; Reid, L. D. Morphine and acceptability of putative reinforcers. Pharmacol. Biochem. Behav. 19:567-569; 1983.

4. Cooper, S. J. Effects of opiate agonists and antagonists on fluid intake and saccharin choice in the rat. Neuropharmacology 22:323-328; 1983.

5. Cooper, S. J.; Jackson, A.; Kirkham, T. C.; Turkish, S. Endorphins, opiates and food intake. In: Rodgers, R. J.; Cooper, S. J., eds. Endorphins, opiates and behavioral processes. New York: John Wiley and Sons; 1988:143-186.

6. Drewnowski, A.; Gosnell, B.; Krahn, D. D.; Canum, K. Sensory preferences for sugar and fat: evidence for opioid involvement. Appetite 12:206; 1989.

7. Evans, K. R.; Vaccarino, F.J. Amphetamine- and morphine-induced feeding: Evidence for involvement of reward mechanisms. Neurosci. Biobehav, Rev. 14:9-22; 1990.

8. Fantino, M.; Hosotte, J.; Apfelbaum, M. An opioid antagonist, naltrexone, reduces preference for sucrose in humans. Am. J. Physiol. 252:R91-R96; 1986.

9. Gosnell, B. A.; Majchrzak, M. J. Centrally administered opioid peptides stimulate saccharin intake in non-deprived rats. Pharmacol. Biochem. Behav. 33:805-810; 1990.

10. Gosnell, B. A.; Majchrzak, M. J. Effects of a selective mu opioid receptor agonist and naloxone on the intake of sodium chloride solutions. Psychopharmacology (Berlin) 100:66-71; 1990.

11. Gosnell, B. A.; Majchrzak, M. J.; Krahn, D. D. Effects of preferential delta and kappa opioid receptor agonists on the intake of hypotonic saline. Physiol. Behav. 47:601-603; 1990.
12. Le Magnen, J.; Marfaing-Jallat, P.; Micelli, D.; Devos, M. Pain modulating and reward systems: A single brain mechanism? Pharmacol. Biochem. Behav. 12:729-733; 1980.

13. Marks-Kaufman, R. Increased fat consumption induced by morphine administration in rats. Pharmacol. Biochem. Behav. 16:949-955; 1982.

14. Marks-Kaufman, R.; Kanarek, R. B. Morphine selectively influences macronutrient intake in the rat. Pharmacol. Biochem. Behav. 12: $427-430 ; 1980$.

15. Marks-Kaufman, R.; Kanarek, R. B. Diet selection following a chronic morphine and naloxone regimen. Pharmacol. Biochem. Behav. 35:665-669; 1990.

16. Marks-Kaufman, R.; Lipeles, B. J. Patterns of nutrient selection in rats orally self-administering morphine. Nutr. Behav. 1:33-46; 1982.

17. Ottaviani, R.; Riley, A. L. Effect of chronic morphine administration on the self-selection of macronutrients in the rat. Nutr. Behav. 2:27-36; 1984 .

18. Reed, D. R.; Contreras, R. J.; Maggio, C.; Greenwood, M. R. C.; Rodin, J. Weight cycling in female rats increases dietary fat selection and adiposity. Physiol. Behav. 42:389-395; 1988.

19. Romsos, D. R.; Gosnell, B. A.; Morley, J. E.; Levine, A. S. Effects of kappa opiate agonists, cholecystokinin and bombesin on intake of diets varying in carbohydrate-to-fat ratio in rats. J. Nutr. 117: 976-985; 1987.

20. Schemmel, R.; Mickelson, O.; Gill, J. L. Dietary obesity in rats: body weight and body fat accretion in seven strains of rats. J. Nutr. 100:1941-1948; 1970.

21. Shor-Posner, G.; Azar, A. P.; Filart, R.; Tempel, D.; Leibowitz, S. F. Morphine-stimulated feeding: Analysis of macronutrient selection and paraventricular nucleus lesions. Pharmacol. Biochem. Behav. 24:931-939; 1986

22. Yeomans, M. R.; Wright, P.; Macleod, H. A.; Critchley, J. A. J. H. Effects of nalmefene on feeding in humans; dissociation of hunger and palatability. Psychopharmacology (Berlin) 100:426-432; 1990. 